\title{
Group decision-making for the thermal renovation of masonry buildings in Algeria
}

\author{
M. Seddiki ${ }^{1}, \mathrm{~K}$. Anouche $^{1}$ \& A. Bennadji ${ }^{2}$ \\ ${ }^{I}$ The University of Science and Technology Mohamed Boudiaf, Algeria \\ ${ }^{2}$ The Robert Gordon University, UK
}

\begin{abstract}
In Algeria, the residential and tertiary sectors are the ones with the highest energy consumption making use of $34 \%$ of the total energy. The government has launched a thermal renovation program for existing buildings to reduce energy consumption. The existing stock has 1,050,000 of masonry dwellings built before 1945. Masonry buildings represent a cultural heritage; they are subject to a building rehabilitation program. The thermal renovation of masonry buildings would both guarantee their preservation and reduce energy consumption. Thermal renovation of masonry buildings in Algeria requires a comprehensive approach; it simultaneously involves a multitude of decision makers (actors concerned with the preservation of buildings, actors concerned by the reduction of energy consumption, owners, etc.) that can express a multitude of criteria (economic, energy, cultural, historical, societal, etc.). This paper presents a method for group decision making based on the Preference Ranking Organization Method for Enrichment Evaluation (PROMETHEE) methods for the thermal renovation of masonry buildings. The aim of the proposed method is to rank different thermal renovation solutions using a multi-criteria and multi-decision makers' approach. The method uses the structured group interaction method Delphi through which the decision group would define the evaluation criteria and the thermal renovations solutions, the group decision support system PROMETHEE GDSS to reach a global ranking of the renovations solutions and PROMETHEE V (optimization under constraints) to introduce additional constraints, the Graphical Analysis for Interactive Aid (GAIA) plan to get a better understanding of conflicts and similarities between the criteria and among the decision makers.

Keywords: thermal renovation, masonry buildings, PROMETHEE methods, multi-criteria decision making, group decision.
\end{abstract}




\section{Introduction}

The Algerian government launched in 2016 a national energy-saving program to reduce the high energy consumption in the residential sector. This program is led by the national agency for the promotion and the rationalization of the energy use (APRUE). Its aim is the thermal insulation of 100,000 houses per year; the national fund for energy management (FNME) will provide 80 percent of the costs related to these interventions (Abdelkader [1]).

Masonry buildings constitute a large part of the existing housing stock in Algeria. The majority of masonry buildings were built during the French colonial period. These buildings represent a valuable architectural heritage. They were constructed according to traditional techniques and materials, with load bearing walls of stone masonry, vaulted brick floor and metal beams (Heraou [2]). The masonry buildings are subject in Algeria to a wide preservation program; indeed, many buildings rehabilitations are undertaken across the country. In 2016, the government envisages the diagnostics of 300,000 dwellings. Rehabilitation operations will be launched following these diagnostics. These actions will be conducted and financed by the government. The buildings rehabilitation will concern only common parts of buildings (exterior facades, yard, cellars, entrance halls, stairwell, accessible and inaccessible terraces, and pitched roofs) (Addab [3]).

The energy-saving program in the residential sector and the rehabilitation of masonry buildings program offer a great opportunity to perform the thermal renovation of masonry buildings. It would balance between the improvement of the thermal performance of the existing buildings stock and the perseveration of masonry buildings. The choice of improvement alternatives during their thermal renovation is a complex decision; it involves different stakeholders that can express a multitude of criteria.

Due to the multi-decision makers and multi-criteria character of the thermal renovation of masonry buildings in Algeria it is difficult to find solutions that can optimize all the criteria at once. Therefore, it would be more appropriate to find consensus solutions. The multiple-criteria decision analysis is a useful tool for this type of problem; it evaluates different solutions taking into account both the preferences of decision makers and the different criteria. This paper suggests a group decision aid method based on PROMETHEE methods (Brans and Vincke [4]) for the thermal renovation of masonry buildings. The aim of the proposed method is to rank different thermal renovation solutions using a multi-criteria and multi-decision makers approach. This paper is divided into five-part, the following section presents a state of art concerning the application of multi-criteria decision aid methods in the field of thermal renovation, part 3 develops the method used in this paper, part 4 provided the results of the application of the method to a case study and finally, section 5 presents our conclusions and directions for future research. 


\section{Literature review}

\subsection{Multi-criteria decision aid method and thermal renovation}

Rey [5] proposed an outranking multi-criteria decision aid method with partial aggregation from the ELECTRE (ELimination and Choice Expressing the REality) family for the thermal renovation of office buildings. Outranking methods were also applied to the study of air conditioning systems (Rutman et al. [6]). The advantage of this approach is that it allows one to take into account both quantitative and qualitative criteria without having to do any coding, it does not allow compensation between criteria, such as facing two actions a and b. It is based on the assumption that a outranks $b$ if $a$ is at least as good as $b$ on a majority of criteria without being too much worse in other criteria.

Roulet et al. [7] suggested a multi-criteria rating methodology based on a complete aggregation approach in order to assess the effectiveness of various thermal renovation scenarios. Blondeau et al. [8] tested MAUT (Multi-Attribute Utility Theory) technique in the study of summer ventilation strategies in an educational building. The findings highlighted the limitations of this method. It is completely compensatory and it provides sometimes counter-intuitive results. Alanne [9] applied a multi-criteria decision aid model type knapsack to help designers to choose the most appropriate renovation actions during the design phase of a project. The advantage of this model is to treat a portfolio optimization case by introducing constraints. The disadvantage is the purely additive character of the model. The complete aggregation approach gives a note to all scenarios and has the advantage that the score is based on the most important criteria however, this approach presents disadvantage it allows the compensation of low score in criteria with good results on several other criteria also it is necessary to carry out a coding to take into account both quantitative and qualitative criteria.

Medineckiene and Björk [10] applied the multi-criteria decision aid method SAW (Simple Additive Weighting), EW (Multiplicative Exponential Weighting) and COPRAS (Complex Proportion Assessment) to choose solutions for the thermal renovation of Swedish residential apartments. Kontu et al. [11] proposed the multi-criteria decision aid method SMAA (Stochastic Multicriteria Acceptability Analysis) to assess which heating system would be best for new single-family homes. The advantage of both approaches cited in this paragraph is to involve the owners nearby the experts using interviews for the first method and questionnaire for the second to get preferences information regarding different evaluations criteria.

The multi-criteria decision aid method was often used in the literature in the field of thermal renovation of buildings. None of these studies concern the thermal renovation of masonry buildings with a heritage value. No study takes into account at the same time, a multitude of criteria expressed by several decision makers to classify the thermal renovation solutions, additional constraints such as the number of action selected and incompatibility between actions to get an accurate classification, conflicts and similarities between the criteria and among decision makers for a better understanding of the decision problem. Also, there is no 
application of the multi-criteria decision aid methods PROMETHEE in this area in the literature.

PROMETHEE multi-criteria decision aid methods could be the basis of a group decision method. It would be applied for the thermal renovation of masonry buildings in Algeria to rank the thermal renovation solutions.

\subsection{PROMETHEE methods}

PROMETHEE methods are outranking methods that use the partial aggregation. They are useful in the case where the number of alternative to rank is finite. These approaches consist to compare the actions pairwise, and to check under certain conditions if one of two actions clearly outrank the other or not from these comparisons. They allow a comprehensive ranking of the various alternatives (Macharis et al. [12]). Behzadian et al. [13] have provided a large state of art in terms of the application of the PROMETHEE method in various areas.

The advantage of PROMETHEE methods is that they use the partial aggregation. They allow one to take into account several quantitative and qualitative criteria without having to do any coding or change the indicators. They do not allow compensation between criteria. With PROMETHEE GDSS it is possible to take into account simultaneously a multitude of criteria expressed by several decision makers to get a global ranking of the alternatives. PROMETHEE $\mathrm{V}$ allows taking into account additional constraints, such as the number of alternatives to selected and incompatibility between two alternatives. Finally, GAIA analysis and sensitivity analysis provides information on conflicts, similarities between the criteria and among the decision makers.

\section{Methodology}

This section presents a group decision aid method based on PROMETHEE methods to evaluate different renovation solutions. The method consists of several steps: first, the group decision is constituted, then the building is investigated. Then, after through Delphi method the criteria and the thermal renovation solutions are defined. With interviews each decision maker provides information between the criteria expressed by weight, and information within the same criterion expressed by the preferences functions. The rest of the calculations will be completed via PROMETHEE methods. The details of the proposed methodology are presented as follows.

\subsection{Constitution of a group decision}

The first step is to form a group of decision makers consisting of (an actor concerned with the preservation of buildings, an actor concerned by the reduction of energy consumption, owners, experts, etc.) involved in the thermal renovation project. 


\subsection{Full investigation on the building}

Following the constitution of the decision makers group, to sensitize the various decision makers about the current situation of the building, a complete documentation of the building would be carried (exanimating the climate zone, the internal organization, the construction method, the aesthetics of the building, the energy consumption etc.).

\subsection{Evaluation criteria}

The thermal renovations solution will be evaluated on a multiple criteria basis. The definition of the evaluation criteria requires the application of several rounds of Delphi method. Keeney et al. [14] provided an excellent study on its application. First, with interview each decision maker is asked individually to express his evaluation criteria taking into account different aspects: economic, environmental, cultural, architectural and social. The criteria can be for example (investment cost, energy consumption decrease, summer comfort, etc.). Secondly, all these criteria have to be combined to form a complete list. This list is shared with all decision-makers. They are invited to review this information and to revise and to resubmit their initial individual list. This process is repeated until the participants decided that they cannot reduce the number of criteria in the list.

\subsection{Alternative generations}

Once the investigation on the building is completed and the evaluation criteria are defined, the group decision makers have to formulate thermal renovation alternatives. The thermal renovation solutions will take into account only the common area, and will concern only the insulation of the building envelope (external roof insulation, external wall insulation, etc.). This step can be performed with an open discussion among decision makers or through the same process used for the evaluation criteria selection.

\subsection{Alternative evaluation with respect to criteria}

Each alternative must be evaluated in term of all the criteria. These evaluations can be quantitative (obtained from thermal dynamic simulation tool, accounting calculations etc.) or qualitative (expert judgments, interviews etc.).

\subsection{Determination of weights and preference functions}

In this step, using interviews each decision maker provides information between the criteria expressed by weights (wj). Then information within the same criterion expressed by the preference functions $(\operatorname{Pj}(a, b))$ should be specified. They represent for each pair of alternatives $a, b$, the preference intensity of an over $b$. A multicriteria preference index is defined as in eqn (1). 


$$
\pi(a, b)=\sum_{j=1}^{k} w_{j} \times P_{j}(a, b)
$$

where $\pi(a, b)$ expresses the preference degree of a over b regarding all the criteria, it varies from 0 to1.

Each decision maker should provide a weight for each criterion. A weight $\mathrm{Wj}$ may be given for criterion $\mathrm{j}$, it varies from 0 to 100 according to the importance that decision-maker gives to this criterion. The weight 100 represents the maximum importance. To facilitate the process of selecting the preference function, a facilitator should help the decision-makers to choose their preference functions. There are six different types of criterion according to their preference functions (Brans et al. [15]). Also, decision makers should specify the threshold values $\mathrm{p}$ (strict preference threshold when the difference between two actions a and $b$ is very strong and very important to the decision maker) and $q$ (indifference threshold when the difference between the actions $a$ and $b$ is insignificant).

\subsection{Individual ranking PROMETHE II and GAIA}

The information obtained in the previous step will be used to compare the actions. First the leaving flow and the entering flow have to be calculated:

The leaving flow Phi+ $(\varnothing+)$ represents a strength measure. It is a number between 0 and 1; this means that for a given action if the leaving flow is 1 the action is preferable to all the others actions on all the criteria and, if the leaving flow is equal to 0 this means that the action does not represent any advantage over the other actions, Phi+ is calculated with eqn (2)

$$
\emptyset^{+}(a)=\frac{1}{n-1} \sum_{b \neq a} \pi(a, b)
$$

The entering flow Phi- (Ø) represents a weakness measure. It is a number between 0 and 1 , where 0 is the best solution and 1 the worst one. Phi-is calculated with eqn (3)

$$
\emptyset^{-}(a)=\frac{1}{n-1} \sum_{b \neq a} \pi(a, b)
$$

Secondly, we calculate the net flow Phi $(\varnothing)$. It represents the difference between the two flows as shown in eqn (4). The net flow allows establishing a comprehensive ranking of actions. Then the decision problem is represented with the GAIA plan.

$$
\emptyset(a)=\emptyset^{+}(a)-\emptyset^{-}(a)
$$




\subsection{Introduction of additional constraints with PROMETHEE V}

A linear program is used to take into account additional constraints. A binary variable $(0-1) \mathrm{xi}$ is associated with each action ai: $\mathrm{xi}=1$ means that the action ai is selected, $x i=0$ means it is not. The aim is to select the actions so that the sum of the Phi (Ø) of these actions is maximum (as shown in eqn (5)).

$$
\max \sum_{i=1}^{n} \emptyset\left(a_{i}\right) x_{i}
$$

\subsection{Global ranking: GDSS PROMETHEE and GAIA analysis}

The global net flow of the group decision can be obtained directly by the weighted sum of the individual flows eqn (6). The global flow for a given alternative is express as follows:

$$
\emptyset_{g}(a)=\sum_{s=1}^{s} w_{s} \emptyset^{s}(a)
$$

where $\mathrm{W}_{\mathrm{s}}$ is the normalized weight assigned to each DMs.

The global net flows provide directly the PROMETHEE GDSS ranking of the alternatives following the group decision preferences. Later the GAIA plane is used but this time for the global ranking. It contributes to understand the preferences of the different decision makers.

\section{Case study}

An apartment situated on the top floor of a neoclassical colonial collective building located in Oran Algeria was adopted as a case study to test the method. The case study was constructed in masonry between the late 19th and early 20th century. Four decision makers (DM) participated in this study; DM1 was a representative of the national agency for the promotion and the rationalization of the energy use (APRUE) in charge of the energy consumption reduction in the residential sector in Algeria. DM 2 represented the department of urban planning and construction (DUC) which has a great experience and an important role in the masonry buildings preservation in Algeria.DM3 was the owner of the selected flat and DM4 was an expert in the thermal renovation of masonry buildings. After the investigation on the building and several rounds of the Delphi method, all the decision makers agreed on 5 evaluation criteria, and 15 thermal renovation alternatives. All the alternatives were evaluated in term of the selected criteria. The evaluation indicators were chosen in such way that they could be easily understood by the group decision. Each decision maker has provided additional information between the criteria expressed by the weight (wj) and information 
within the same criterion expressed by the preference function $(\operatorname{Pj}(a, b))$ (see Table 1).

Under Visual PROMETHEE software (Mareschal [16]) it was possible to get an individual ranking PROMETHE II for each decision maker (see Table 2). For this purpose, additional constraints (number of actions to select, incompatibilities between actions) were added since there are 15 alternatives and only 4 that can be selected simultaneously. These constraints were taken into account through the PROMETHEE V method.

The constraint of the number of actions to select is indicated in eqn (7).

$$
\sum_{i=1}^{n} x_{i}=4
$$

The constraints of the incompatibilities between actions (A) are indicated in eqns (8), (9), (10), and (11).

$$
\begin{gathered}
\mathrm{A} 1+\mathrm{A} 2+\mathrm{A} 3+\mathrm{A} 4=1 \\
\mathrm{~A} 5+\mathrm{A} 6+\mathrm{A} 7+\mathrm{A} 8=1 \\
\mathrm{~A} 9+\mathrm{A} 10+\mathrm{A} 11+\mathrm{A} 12=1 \\
\mathrm{~A} 13+\mathrm{A} 14+\mathrm{A} 15=1
\end{gathered}
$$

Table 2 shows that the ranking of the thermal renovation solutions was different for almost all decision makers .DM1 and DM3 provided a similar ranking. DM4 provided a ranking close to DM1 and DM3 with A9 and A7 in the top row. The only difference is that $\mathrm{A} 13$ is in the third position and $\mathrm{A} 4$ is preferred to A3. DM2 had a completely different ranking, it should be noted from this individual ranking that there is two different group; DM1, DM3 and DM4 who had almost a similar ranking and DM2 which had completely different preferences.

The net flow of the 4 decision makers was collected together in a global decision matrix (as indicated in table 3). A PROMETHEE GDSS global ranking was performed with the same constraints used in the individual ranking. According to the group decision viewpoint the actions A9, A7, A4, A13 are respectively preferable to all the other actions (see Fig. 1). The global ranking was accepted by all the decision makers. They all agreed that the selected actions represent the best compromise. 
Table 1: Evaluation table.

\begin{tabular}{|c|c|c|c|c|c|c|c|}
\hline & & Criteria & \multirow{2}{*}{ 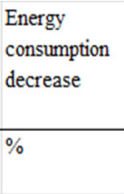 } & \multirow{2}{*}{$\begin{array}{l}\text { Investment } \\
\text { cost Algérien } \\
\text { Algerian } \\
\text { dinars }\end{array}$} & \multirow{2}{*}{\begin{tabular}{|l}
$\begin{array}{l}\text { Summer } \\
\text { comfort }\end{array}$ \\
Hour \\
\end{tabular}} & \multirow{2}{*}{$\begin{array}{l}\text { Risk of loss } \\
\text { of building } \\
\text { historic } \\
\text { aesthetic } \\
\text { Qualitative }\end{array}$} & \multirow{2}{*}{$\begin{array}{l}\text { Risk of fabric } \\
\text { decay }\end{array}$} \\
\hline & & Unit & & & & & \\
\hline & \multirow[t]{3}{*}{ DM1 } & Weight & 100 & 85 & 75 & 40 & 80 \\
\hline & & Preference function & $\mathrm{U}$ & Usual & $\mathrm{U}$ & Usual & Usual \\
\hline & & Threshold values & $q=3$ & & $q=2$ & & \\
\hline & \multirow[t]{3}{*}{ DM2 } & Weight & 0 & 40 & 0 & 90 & 90 \\
\hline & & Preference & & Usual & & Usual & Usual \\
\hline & & Threshold values & & & & & \\
\hline & \multirow[t]{3}{*}{ DM3 } & Weight & 85 & 95 & 80 & 30 & 70 \\
\hline & & Preference function & $\mathrm{U}$ & Usual & $\mathrm{U}$ & Usual & Usual \\
\hline & & Threshold values & $q=3$ & & $q=10$ & & \\
\hline & \multirow[t]{3}{*}{ DM4 } & Weight & 90 & 75 & 75 & 90 & 85 \\
\hline & & Preference function & $\mathrm{U}$ & Usual & $\mathrm{U}$ & Usual & Usual \\
\hline & & Threshold values & $q=3$ & & $q=10$ & & \\
\hline & \multicolumn{2}{|c|}{$\begin{array}{l}\text { A1 Exterior insulation of the main facade with } 10 \\
\mathrm{~cm} \text { of expanded polystyrene }\end{array}$} & 11 & 50000 & 252 & Very high & Very high \\
\hline $\begin{array}{l}\mathrm{T} \\
\mathrm{h}\end{array}$ & \multicolumn{2}{|c|}{$\begin{array}{l}\text { A2 Exterior insulation of the main facade with } 10 \\
\mathrm{~cm} \text { of cellular concrete }\end{array}$} & 11 & 70000 & 250 & Very high & Low \\
\hline $\begin{array}{l}\mathrm{r} \\
\mathrm{m}\end{array}$ & \multicolumn{2}{|c|}{$\begin{array}{l}\text { A3 Exterior insulation of the main facade with } 10 \\
\mathrm{~cm} \text { of wood fiber }\end{array}$} & 11 & 55000 & 256 & Very high & Low \\
\hline $\begin{array}{l}a \\
1\end{array}$ & \multicolumn{2}{|c|}{$\begin{array}{l}\text { A4 Exterior insulation of the main facade with } 6 \mathrm{~cm} \\
\text { of lime hemp plaster }\end{array}$} & & 60000 & 256 & Very low & Very low \\
\hline $\mathrm{r}$ & \multicolumn{2}{|c|}{$\begin{array}{l}\text { A5 Exterior insulation of the secondary facade and } \\
\text { courtyard with } 10 \mathrm{~cm} \text { of expanded polystyrene }\end{array}$} & 9 & 40200 & 256 & Medium & Very high \\
\hline $\begin{array}{l}\mathrm{e} \\
\mathrm{n} \\
\mathrm{o}\end{array}$ & \multicolumn{2}{|c|}{$\begin{array}{l}\text { A6 Exterior insulation of the secondary facade and } \\
\text { courtyard with } 10 \mathrm{~cm} \text { of cellular concrete }\end{array}$} & 9 & 56280 & 254 & Medium & Low \\
\hline $\mathrm{v}$ & \multicolumn{2}{|c|}{$\begin{array}{l}\text { A7 Exterior insulation of the secondary facade and } \\
\text { courtyard with } 10 \mathrm{~cm} \text { of wood fiber }\end{array}$} & 9 & 44220 & 258 & Medium & Low \\
\hline $\begin{array}{l}\mathrm{t} \\
\mathrm{i}\end{array}$ & \multicolumn{2}{|c|}{$\begin{array}{l}\text { A8 Exterior insulation of the secondary facade and } \\
\text { courtyard with } 6 \mathrm{~cm} \text { of lime hemp plaster }\end{array}$} & 6 & 48240 & 258 & Very low & Very low \\
\hline n & \multicolumn{2}{|c|}{$\begin{array}{l}\text { A9 Exterior insulation of the roof with } 10 \mathrm{~cm} \text { of } \\
\text { expanded polystyrene }\end{array}$} & 26 & 145000 & 132 & Very low & Low \\
\hline $\mathrm{s}$ & \multicolumn{2}{|c|}{$\begin{array}{l}\text { A10 Exterior insulation of the roof with } 10 \mathrm{~cm} \text { of } \\
\text { wood fiber }\end{array}$} & 26 & 159500 & 142 & Very low & Low \\
\hline 1 & \multicolumn{2}{|c|}{$\begin{array}{l}\text { A11 Exterior insulation of the roof with } 15 \mathrm{~cm} \text { of } \\
\text { expanded polystyrene }\end{array}$} & 29 & 217500 & 120 & Very low & Low \\
\hline $\mathrm{t}$ & \multicolumn{2}{|c|}{$\begin{array}{l}\text { A12 Exterior insulation of the roof with } 15 \mathrm{~cm} \text { of } \\
\text { wood fiber }\end{array}$} & 29 & 232000 & 129 & Very low & Low \\
\hline $\begin{array}{l}0 \\
\mathrm{n}\end{array}$ & \multicolumn{2}{|c|}{ A13 Double glazing window installation. } & 21 & 227500 & 242 & Medium & - \\
\hline s & \multicolumn{2}{|c|}{ A14 Double windows installation } & 19 & 233400 & 245 & Very low & - \\
\hline & \multicolumn{2}{|c|}{ A15 Secondary glazing installation } & 9 & 70000 & 258 & Very low & - \\
\hline
\end{tabular}


544 The Sustainable City XI

Table 2: Individual PROMETHEE II ranking.

\begin{tabular}{|l|l|l|l|l|}
\hline Ranking & DM1 & DM2 & DM3 & DM4 \\
\hline 1 & A9 & A8 & A9 & A9 \\
\hline 2 & A7 & A4 & A7 & A7 \\
\hline 3 & A3 & A9 & A3 & A13 \\
\hline 4 & A13 & A15 & A13 & A4 \\
\hline
\end{tabular}

Table 3: $\quad$ Global decision matrix.

\begin{tabular}{|l|l|l|l|l|}
\hline Action & DM1 & DM2 & DM3 & DM4 \\
\cline { 2 - 4 } & net flow & net flow & net flow & net flow \\
\hline A1 & -0.154 & -0.428 & -0.119 & -0.296 \\
\hline A2 & -0.117 & -0.25 & -0.122 & -0.236 \\
\hline A3 & -0.005 & -0.118 & -0.021 & -0.172 \\
\hline A4 & -0.163 & 0.173 & -0.181 & -0.115 \\
\hline A5 & -0.095 & -0.338 & -0.071 & -0.136 \\
\hline A6 & -0.075 & 0.105 & -0.077 & -0.076 \\
\hline A7 & 0.052 & 0.205 & 0.057 & 0.062 \\
\hline A8 & -0.035 & 0.273 & -0.03 & 0.06 \\
\hline A9 & 0.328 & 0.099 & 0.296 & -0.012 \\
\hline A10 & 0.296 & 0.074 & 0.243 & 0.323 \\
\hline A11 & 0.264 & 0.049 & 0.268 & 0.284 \\
\hline A12 & 0.2 & 0 & 0.177 & 0.246 \\
\hline A13 & -0.122 & -0.124 & -0.056 & -0.012 \\
\hline A14 & -0.186 & -0.08 & -0.147 & -0.031 \\
\hline A15 & -0.185 & 0.08 & -0.215 & -0.136 \\
\hline & & & & \\
\hline
\end{tabular}

Phi 0.261

\section{A7}

Phi 0.093
A4

Phi -0.071
Phi -0.079

where Phi is the global net flow of the group decision for each action.

Figure 1: Global ranking PROMETHEE GDSS. 


\section{Conclusions}

The relevance of this paper is that it considers the thermal renovation of masonry buildings as a complex decision involving different stakeholders with different objectives. The literature review highlighted the lack of study regarding the application of multi-criteria decision aid method in the thermal renovation of masonry buildings with a heritage value when different stakeholders are involved. This paper has also an innovative value due to the proposal of a group decision aid method based on PROMETHEE methods in the field of thermal renovation of masonry buildings. The aim of the proposed method is to rank different thermal renovation solutions using a multi-criteria and multi-decision makers approach, the method uses:

- $\quad$ PROMETHEE GDSS group decision aid method to take into account a multitude of criteria expressed by several decision makers.

- $\quad$ PROMETHEE V method to add constraints.

- $\quad$ GAIA plan for a better understanding of the conflicts and similarities between the criteria and among decision makers.

A case study was presented to test the applicability of the method in the thermal renovation of masonry buildings. The results showed that the method works and that it was possible to get a full ranking of the renovation solutions. From the group decision viewpoint, the best solutions were respectively A9, A7, A4, A13.The proposed group decision method allowed the decision makers for a better comprehension of the available thermal renovation alternatives and the essential consensus required to reach a better decision result. The application of the method to the case study has considered only one flat and one owner. It would be relevant for future research to test the application of the method to a whole building and to take into account the preferences of all owners.

\section{References}

[1] Abdelkader B. Lancement du nouveau programme d'efficacité énergétique en 2016. [home page on the Internet]. Oran: SARL Edimarcom-Dist; 2015 cited 201526 June]. Available from: http://www.carrefourdalgerie.com/ archive/pdf/2015/04/16-04-2015.pdf.

[2] Heraou A. Evolution des Politiques de l'habitat en Algerie. [Magister Option: Habitat thesis on the Internet]. Université de Sétif; 2011 [cited 26 June 2015] Available from:http://www.univsetif.dz/MMAGISTER/images/ facultes/ARCH/HERAOU\%20ABDELKRIM.pdf

[3] Addab M. Réhabilitation du vieux bâti: Diagnostic de plus de 300.000 logements. [homepage on the Internet]. Oran: Le Quotidien; 2015 cited 20153 June 2015]

[4] J. P. Brans and Ph. Vincke. A Preference Ranking Organisation Method: (The PROMETHEE Method for Multiple Criteria Decision-Making). Management Science, 31, pp. 641-656, 1985. 
[5] Rey E. Office building retrofitting strategies: multicriteria approach of an architectural and technical issue. Energy and Buildings, 36(4), pp. 367372, 2004.

[6] Rutman E, Inard C, Bailly A, Allard F. A global approach of indoor environment in an air-conditioned office room. Building and Environment, 40(1), pp. 29-37, 2005.

[7] Roulet C, Flourentzou F, Labben HH, Santamouris M, Koronaki I, Dascalaki E, et al. ORME: A multicriteria rating methodology for buildings. Building and Environment, 37(6), pp. 579-586, 2002.

[8] Blondeau P, Spérandio M, Allard F. Multicriteria analysis of ventilation in summer period. Building and Environment, 37(2), pp. 165-176, 2002.

[9] Alanne K. Selection of renovation actions using multi-criteria "knapsack" model. Automation in Construction, 13(3), pp. 377-391, 2004.

[10] Medineckiene M, Björk F. Owner preferences regarding renovation measures - the demonstration of using multi-criteria decision making. Journal of civil engineering and management. 17(2), pp. 284-295, 2011.

[11] Kontu K, Rinne S, Olkkonen V, Lahdelma R, Salminen P. Multicriteria evaluation of heating choices for a new sustainable residential area. Energy and Buildings, 93, pp. 169-179, 2015.

[12] Macharis C, Springael J, De Brucker K, Verbeke A. PROMETHEE and AHP: The design of operational synergies in multicriteria analysis: Strengthening PROMETHEE with ideas of AHP. European Journal of Operational Research, 153(2), pp. 307-317, 2004.

[13] Behzadian M, Kazemzadeh RB, Albadvi A, Aghdasi M. PROMETHEE: A comprehensive literature review on methodologies and applications. European Journal of Operational Research, 200(1), pp. 198-215, 2010.

[14] Keeney S, Hasson F, McKenna H. Consulting the oracle: ten lessons from using the Delphi technique in nursing research. Journal of advanced nursing, 53(2), pp. 205-212, 2006.

[15] Brans JP, Vincke P, Mareschal B. How to select and how to rank projects: The Promethee method. European Journal of Operational Research, 24(2), pp. 228-238, 1986.

[16] VPSOLUTIONS, Mareschal B. The Visual PROMETHEE Academic Edition, 2012. 